\title{
Prevalence of Cardiovascular Risk Factors among the Nurse Population in the East of Iran
}

\author{
Toba Kazemi ${ }^{1}$, Gholamreza Sharifzadeh ${ }^{2}$, Seyyed Alireza Javadinia ${ }^{3,}{ }^{*}$, Hamid Salehiniya ${ }^{4}$ \\ ${ }^{1}$ Atherosclerosis and Coronary Artery Research Centre, Birjand University of Medical Sciences (BUMS), Birjand, Iran \\ ${ }^{2}$ Hepatitis Research Center, Birjand University of Medical Sciences (BUMS), Birjand, Iran \\ ${ }^{3}$ Student Research Committee, Birjand University of Medical Sciences (BUMS), Birjand, Iran \\ ${ }^{4}$ Tehran University of Medical Sciences, Tehran, Iran
}

*Corresponding Author: Seyyed Alireza Javadinia, MD, Student Research Committee, Birjand University of Medical Sciences (BUMS), Birjand, Iran. Email: javadinia.alireza@yahoo.com

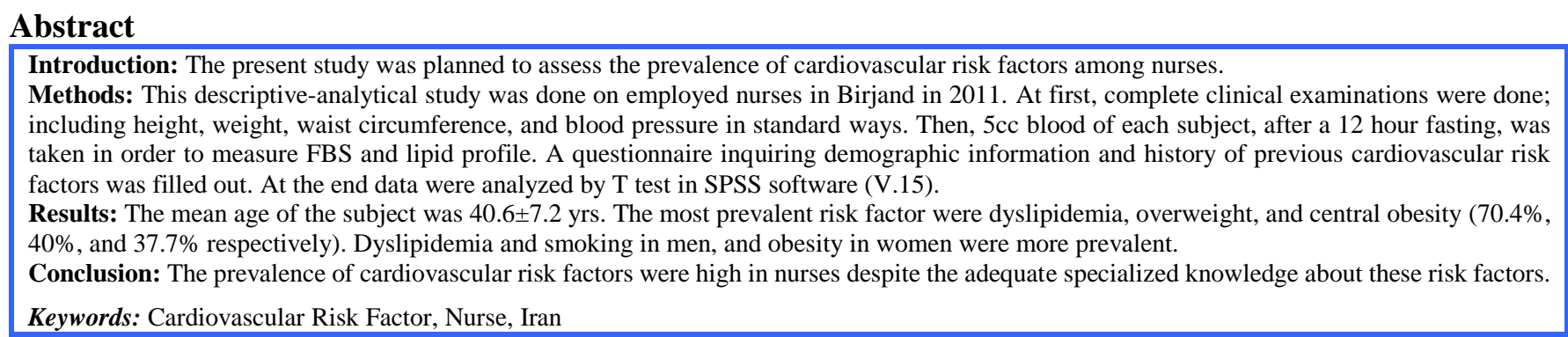

Article History: Received: 8 Apr. 2015; Accepted: 15 Jul. 2015; Online Published: 26 Nov. 2015

Cite this article as: Kazemi T, Sharifzadeh G, Javadinia SA, Salehiniya H. Prevalence of cardiovascular risk factors among the nurse population in the east of Iran. Int J Travel Med Glob Health. 2015;3(4):133-6.

\section{Introduction}

Cardiovascular diseases (CVD) are one of the most important causes of death throughout the world [1]. These diseases are the reason for $30 \%$ of mortalities in Iran and the rest of the world [2]. During recent years, due to industrialization development of communities and citizenship, extensive changes have occurred in the life style of people having different races and culture [2, 3]. In the Middle East, these changes have revealed in the form of replacing a rich fiber, low cholesterol and fat diet, with a low fiber, rich in cholesterol and fat one. As a result, obesity and inactivity have extensively been increasing $[4,5]$. Such changes have caused cardiovascular diseases [6]. Regarding the chronic nature of these diseases, they can increase mortality rate, disability, lowering life style status, imposing great expense on health systems, and social problems.

The underlying risk factors of these diseases are of various types. Among them, smoking, diet, and insufficient physical activity, as behavioral risk factors; and dyslipidemia, hypertension, obesity, and Diabetes Mellitus (DM), as metabolic risk factors, are of utmost importance [1, 7]. Various studies have shown that these factors have a relatively high prevalence in both patients with Ischemic heart diseases and across the whole community $[6,8]$.

However, CVD are among the most preventable chronic diseases of man; and if they are controlled their probable damages in and their imposed expense on the health system of every community will decrease [9].

Nurses are the backbone of health systems throughout the world and have a critical role in the health systems, health education, and prevention of diseases. Thus, they act as a practical model of healthy life for both patients and the community $[10,11]$. These health care workers are closely faced with and aware of $\mathrm{CV}$ risk factors and their damages
[12]. Therefore, they are expected to do more in the domain of correcting the community's life style and its improvement through deleting CV risk factors [13, 14]. Besides, regarding the educational role of nurses towards patients and their attendants it is reasonable to expect more effective education on the part of the nurses who have a healthier life style and are more aware of their own health risk factors.

Different studies about $\mathrm{CV}$ risk factors in nurse population have shown that a significant number of nurses are prone to an increase in $\mathrm{CV}$ risk factors. Among them smoking, overweight, and lack of regular exercise are the more important ones $[12,15]$.

Since the health of nurses, as one of the basics of any health system, and the necessity of determining the pathologic condition in the community or specific group; and regarding that there was no specific information about the health workers in the east of Iran, the present study was designed aiming at determining $\mathrm{CV}$ risk factors in the nurses of Birjand educational hospitals.

\section{Methods}

The present cross-sectional study was done on the nurses of Birjand educational hospitals. The study protocol had been approved by BUMS' ethical committee. After selecting the study population and taking their written consent, they entered the study.

In order to gather necessary data a self-designed questionnaire on the basis of the aim of the study including demographic information, CV risk factors status, and results of biochemical tests of the cases was used. Content reliability of the questionnaire was confirmed by three of expert academic members. Data collection was done in the following manner: First of all, two trained nursing adepts 
collected demographic data and $\mathrm{CV}$ risk factors through interviewing the cases. Then, the subjects were weighed by means of German Seca scale while they were bare-footed and had the least clothing on; with an error margin of $50 \mathrm{~g}$. Height measurement of the cases was done using a strip meter while they were bare-footed and their heads were attached to the back wall, with an error limit of 0.5 centimeter. Waist circumference parallel to the navel and buttocks circumference regarding its most prominent spot were also measured .Blood pressure of the subjects was measured two times by means of a Mercury sphygmomanometer while they were sitting, with a lapse of 5 minutes under standard condition. All the measurements were done by the same nurse using the same equipment whose accuracy was regularly checked. Then, the obtained data was recorded in the questionnaire. For the assessment of blood factors, $5 \mathrm{cc}$ of blood from each one's brachial vein was extracted after a 12 hour fasting. After preparation and freezing of the samples in the hospital lab, they were simultaneously sent to Imam Reza special clinical lab to undergo FBS, CHOL, LDL, HDL and TG tests.

Diabetic criteria in the present study were $\mathrm{FBS} \geq 126 \mathrm{mg} / \mathrm{dl}$, as diabetes; FBS $110 \mathrm{mg} / \mathrm{dl}-125 \mathrm{mg} / \mathrm{dl}$, as prediabetes; and dyslipidemia indices were Triglyceridemia $>150 \mathrm{mg} / \mathrm{dl}$, Cholesterol >200mg, LDL>130mg/dl ,HDL <40mg/dl (in males) and $\mathrm{HDL}<50$ (in females). Besides, $\mathrm{BP} \geq 140 / 90$ was taken as "Hypertension".

The obtained data was fed into SPSS software (V:13), and after applying descriptive statistics, was analyzed using $\mathrm{X}^{2}$ and t-test at the significant level $\alpha=0.05$.

\section{Results}

The current study was conducted on 453 individuals of Birjand educational hospitals health staff with the mean age of 40.6 $\pm 7.2 \mathrm{yrs}$. Among the subjects, 297 were females $(65.6 \%)$ and $432(95.4 \%)$ were married. Regarding education 192(42.4\%) held a high school diploma or part of high school education, 54(11.9\%) were associates, $176(38.9 \%)$ had B.S. degrees, and $31(6.9 \%)$ had MA or PhD degrees. Among them 14 (3.1\%) were current smokers. The mean BMI of the subjects was $25.8 \pm 4.3 \mathrm{~kg} / \mathrm{m}^{2}$.

Figure 1 illustrates $\mathrm{CV}$ risk factors of the subjects. According to the figure, the most prevalent risk factors in the population under study were dyslipidemia, overweight, and central obesity; i.e. $70.4 \%, 40 \%$, and $37.7 \%$ respectively. As seen, the risk factors "smoking", "diabetes", and "hypertension" had the least prevalence $(3.1 \%, 3.1 \%$, and 9.1\% respectively). As for dyslipidemia, low HDL (44.4\%) were the most and high TG $(24.9 \%)$ were the least prevalent items.

Table 1 also presents a comparative assessment of CV risk factors in the two sexes. It was found that the prevalence of dyslipidemia and smoking was significantly higher in males. However, central obesity was more in females. Regarding diabetes prevalence and the factors overweight, obesity, and hypertension no significant difference was found between the two sexes.

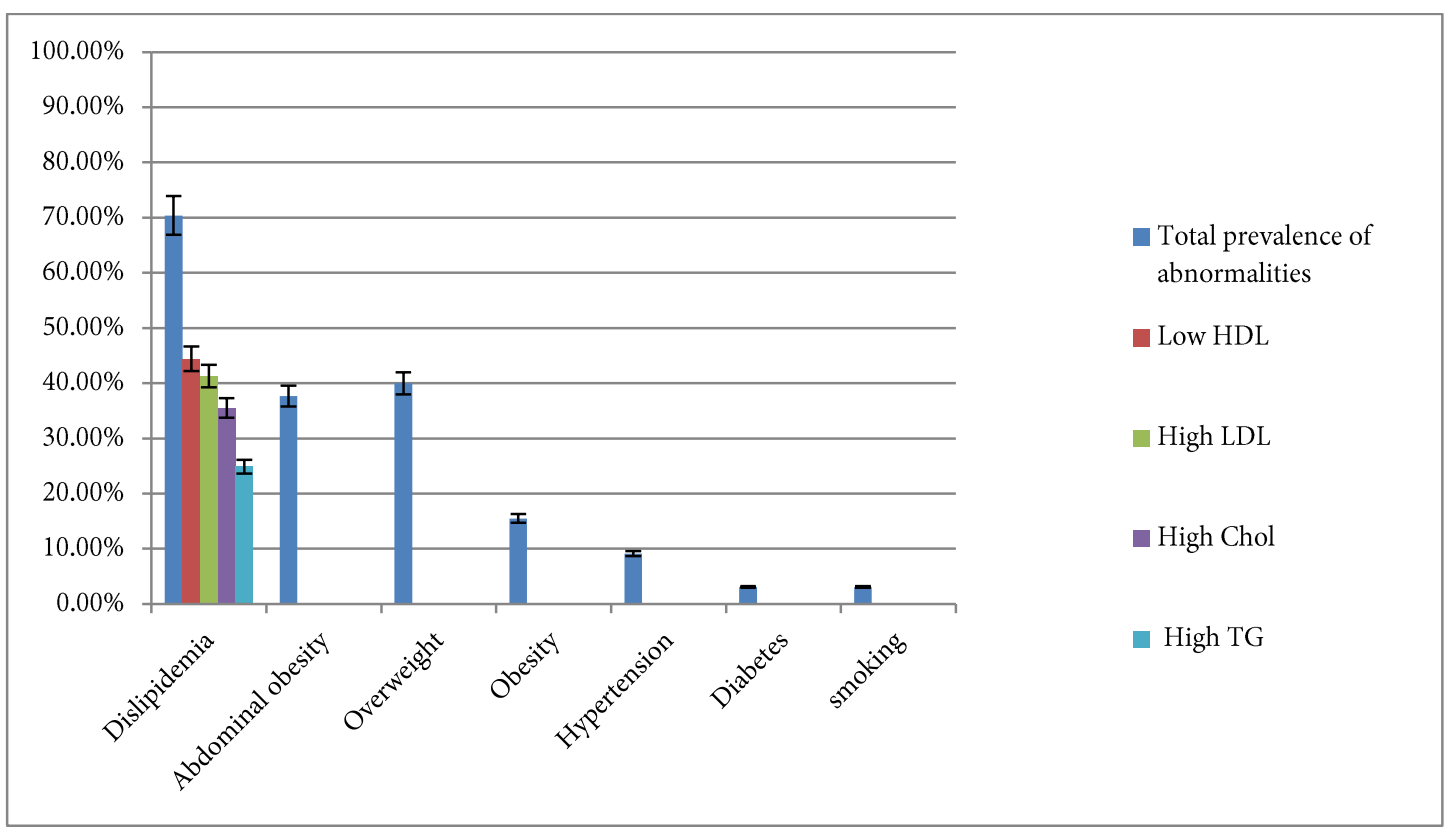

Figure 1. CV risk factors in the population under study

Table 1. Prevalence of CV risk factors with respect to sex in the study population

\begin{tabular}{lccc}
\hline Prevalence Risk Factors & Total N $(\%)$ & Male N=156 & Female N=297 \\
\hline Diabetes & $14(3.09)$ & $8(5.1)$ & $6(2)$ \\
Hypertension & $41(9.05)$ & $17(10.9)$ & $24(8.1)$ \\
Smoking & $14(3.09)$ & $14(9)$ & $0(0)$ \\
Dyslipidemia & $319(70.42)$ & $145(92.9)$ & $174(58.6)$ \\
Low HDL & $201(44.37)$ & $138(88.5)$ & $63(21.3)$ \\
High LDL & $187(41.28)$ & $73(46.8)$ & $114(38.4)$ \\
High CHOL & $161(35.54)$ & $62(39.7)$ & $99(33.3)$ \\
High TG & $113(24.94)$ & $60(38.5)$ & $53(17.8)$ \\
Abdominal obesity & $171(37.74)$ & $41(26.3)$ & $130(43.8)$ \\
Overweight 25 $\geq \mathbf{B M I}>\mathbf{3 0}$ & $181(39.96)$ & $58(37.2)$ & $\mathrm{P}<0.001$ \\
Obesity BMI $\geq \mathbf{3 0}$ & $70(15.45)$ & $18(11.5)$ & $\mathrm{P}=0.08$ \\
\hline
\end{tabular}




\section{Discussion}

The present study was trying to assess CV risk factors in all the employed nurses in the hospitals under the affiliation of BUMS in Birjand. The results of the study showed that dyslipidemia, overweight and central obesity are respectively the most prevalent $\mathrm{CV}$ risk factors.

The most prevalent $\mathrm{CV}$ risk factor was found to be dyslipidemia $(70 \%)$ and it was significantly higher in males than in females. According to Burns' study the most prevalent $\mathrm{CV}$ risk factor was prehypertension. Dyslipidemia (cholesterol $>200 \mathrm{mg} / \mathrm{dl}, \mathrm{HDL}<40 \mathrm{mg} / \mathrm{dl}$ ), with the level of $58 \%$, was ranked the second. No significant statistical difference was observed between dyslipidemia among the nurses and that of the community (62\%) [12]. Fair's study found that the most dominant risk factor was prehypertension and dyslipidemia (15\%) was the second. Both of the above factors were less prevalent in the nurses than the community [13].

In most of the developed countries hypertension and prehypertension have been diagnosed as the greatest $\mathrm{CV}$ factors. Compared with the above studies it is concluded that dyslipidemia prevalence in the nurse's population in Iran is higher than those in other countries. This difference can be due to different diets, amount and type of physical activity, and -perhaps- racial and ecological varieties.

The current study revealed that among different aspects of dyslipidemia low HDL (41.28\%) and high LDL (35.54\%) were the most prevalent.

In Burns' study on nurses in the United States it was found that most dyslipidemia was in the form of high LDL (48\%) and low HDL only in $10 \%$ of the nurses under study [12].This report shows a difference in dyslipidemia factors in the two countries, since low HDL is known as the most prevalent CV risk factor in Iran [16, 17].

Ghazanfaris' study on Kerman citizens indicated that abnormal BMI (46\%) and dyslipidemia (39.8\%) had the first and the second prevalence, respectively [8]. Kazemi in her study discovered that the most prevalent $\mathrm{CV}$ factors in referring patients with infarction were hypertension (34.8\%), smoking (32.1\%), and dyslipidemia (24\%) in a descending order [6]. Another study in the east of Iran found that dyslipidemia, overweight and obesity, addiction to smoking, hypertension, and diabetes were the most significant $\mathrm{CV}$ risk factors [18]. According to a study in Isfahan obesity [19]; in Isfahan's Healthy Heart Study hypertension, dyslipidemia, and smoking [20]; in Amir Shahr in the Mazandaran province, overweight and obesity, hypertension, diabetes, and smoking were the most significant, too [21].

Comparing the results of the present study with those of the above studies reveals that the distribution of $\mathrm{CV}$ risk factors in nurses, the whole population, and other sub-groups in the community are different. Dyslipidemia is the most notorious complication in the nurses, although they are expected to have experienced less prevalence of this in the current study; regarding their awareness of dyslipidemia risks and their interaction with dyslipidemia patients. This is while the obtained results astonishingly showed that the prevalence of such complications in the nurse population is much higher than that of the general population of the country. This indicates more occurrences of CV risk factors in the nurses' population. Thus, it is necessary that promoting measures should be taken in order to improve CV risk factors in the nurses, who act as one of the basics of the health systems.
Based on the findings of the present study the prevalence of overweight and obesity were $39.9 \%$ and $15.4 \%$, respectively. A study in Shiraz found that the prevalence of overweight and obesity were respectively $37.1 \%$ and $17.9 \%$; something similar to what we found [23].These findings are in accord with the increase of obesity prevalence in Asia and in the world [24]. It is evident that obesity and overweight are caused by dietary changes and consuming high calorie foods [25].

Various studies show that obesity and overweight prevalence is more in females [23, 26, 27] and women are severely prone to obesity [28]. Higher prevalence of overweight and obesity in women can be due to their more inactivity [29]. This was while in our study this rate was equal in men and women,

On the basis of the present study, $37.7 \%$ of the subjects had central obesity, which was more prevalent in females; but this prevalence was less than the average $(53.6 \%)$ in the country [22]. However, this percent (i.e.37.7\%) of central obesity was not favorable and required weight decreasing interventions [22].

We found that hypertension prevalence was $9 \%$, while it used to be $10 \%$ in another study in Birjand [18]. In a study conducted in Isfahan it had been $7.7 \%$ [19]. Thus, the prevalence of hypertension in the health workers, who are expected to have a better control, is in agreement with the condition in other studies and of the public.

It was discovered that diabetes prevalence in the health workers was $3.9 \%$. It was higher in males compared to females. Its prevalence degree was close to that of Mazandaran and south khorasan provinces [18, 21]. In comparison with the developed countries [30] and the mean level in Iran [22], the diabetes prevalence was lower, which can be due to less economic and social development of Birjand [30].

The total prevalence of smoking was $3.9 \%$, while it was significantly higher in men compared to women. It had been $6.9 \%$ in Isfahan, $15.5 \%$ in Birjand, $18 \%$ in Amir Shahr [18, 19, 21]. Different studies have shown that the smoking prevalence in men has been more. It is probable that, due to notoriety of being a smoker employed clerk, some individuals' sensitivities and feasible fears, some would have avoided reporting their smoking addiction [31].

In a recent study held out by Jardim et al. the prevalence of CVD risk factors and their changes in different health care professionals over the past 20 years in Brazil (all the students of the Faculties of Medicine, Nursing, Nutrition, Dentistry, and Pharmacy) was assessed (1993-2013).They observed an increase in the prevalence of CVD risk factors in these health care professionals. This may be related to the low activity and highly sedentary activities and on the other hand the high degree of stress in these groups [32].

\section{Conclusion}

Based on the results of the current study, CVD risk factors in the nurses "a population with formal education in health, with appropriate knowledge on CVD and their complication" are high, and educational intervening programs should be outlined to decrease such risk factors in them for a better outcome of their health services.

\section{Acknowledgements}

We are obliged to the participants of this study. We would also like to thank the BUMS research assistant for his 
financial support to this research.

\section{Authors' Contributions}

All authors were involved in the study design and result interpretation. All authors confirmed the final draft before submission.

\section{Financial Disclosure}

The authors declare that they have no financial disclosure.

\section{Funding/Support}

This study was support by the Birjand University of Medical Sciences.

\section{References}

1. Kazemi T, Sharifzadeh G, Zarban A, Fesharakinia A.Comparison of components of metabolic syndrome in premature myocardial infarction in an Iranian population: a case -control study. Int J Prev Med. 2013;4(1):110-4

2. Jamali SM,Izadi M. Deaths: leading causes for 2011-2012. Int J Travel Med Glob Health.2014;2(2):69-80

3. Yusuf S, Vaz M, Pais P. Tackling the challenge of cardiovascular disease burden in developing countries. Am Heart J. 2004;148(1):1 4.

4. Shara N. Cardiovascular disease in Middle Eastern women. Nutr Metab Cardiovasc Dis. 2010;20(6):412-8.

5. Musaiger AO. Diet and prevention of coronary heart disease in the Arab Middle East countries. Med Princ Pract. 2002;11(Suppl. 2):916.

6. Kazemi T, Sharifzadeh G, Hosseinaii F. Epidemiology of Trend of Acute Myocardial Infraction in Birjand between 2002-2006 years. Iran J Epidemiol. 2009;4(3):35-41. Persian

7. Abolhassani S, Irani MD, Sarrafzadegan N, Rabiei K, Shahrokhi S, Pourmoghaddas $Z$, et al. Barriers and facilitators of weight management in overweight and obese people: Qualitative findings of TABASSOM project. Iran J Nurs Midwifery Rese. 2012;17(3):205.

8. Ghazanfari Z, Alizadeh M, Azizzadeh Furozi M, Bahodini N. Prevalence of coronary artery diseases risk factors in Kerman. Iran J Crit Care Nurs. 2010;3(1):29-32.

9. Kazemi T, Sharifzadeh GR, Zarban A, Fesharakinia A, Rezvani MR, Moezy SA. Risk factors for premature myocardial infarction: a matched case-control study. J Res Health Sci. 2011;11(2):77-82.

10. Abazari P, Vanaki Z, Mohammadi E, Amini M. Challenges of training diabetes nurse educator in Iran. Iran J Nurs Midwifery Res. 2012;17(3):187-94

11. Yousefi H, Karami A, Moeini M, Ganji H. Effectiveness of nursing interventions based on family needs on family satisfaction in the neurosurgery intensive care unit. Iran $\mathrm{J}$ Nurs Midwifery Res. 2012;17(4):296.

12. Burns K, Gross B, Zanin M. Cardiovascular risk study: a comparison between northeast Ohio cardiovascular nurses and the nation. J Community Health Nurs. 2010;27(4):187-96.

13. Fair JM, Gulanick M, Braun LT. Cardiovascular risk factors and lifestyle habits among preventive cardiovascular nurses. J Cardiovasc Nurs. 2009;24(4):277-86

14. Miller SK, Alpert PT, Cross CL. Overweight and obesity in nurses, advanced practice nurses, and nurse educators. J Am Acad Nurs Pract. 2008;20(5):259-65.
15. Jaarsma T, Stewart S, De Geest S, Fridlund B, Johanna H, Mårtensson $\mathrm{J}$, et al. A survey of coronary risk factors and B-type natriuretic peptide concentrations in cardiac nurses from Europe: do nurses still practice what they preach? Eur J Cardiovasc Nurs. 2004;3(1):3-6.

16. Hadaegh F, Khalili D, Ghasemi A, Tohidi M, Sheikholeslami F, Azizi F. Triglyceride/HDL-cholesterol ratio is an independent predictor for coronary heart disease in a population of Iranian men. Nutr Metab Cardiovasc Dis. 2009;19(6):401-8.

17. Azizi F, Rahmani M, Emami H, Mirmiran P, Hajipour R, Madjid M, et al. Cardiovascular risk factors in an Iranian urban population: Tehran lipid and glucose study (phase 1). Soz Praventivmed. 2002;47(6):408-26.

18. Kazemi T, Sadeghi-Khorashad M, Salehi-Give A. Evaluation of cardiovascular risk factors in drivers of heavy vehicles in the South Khorasan (2009-2010). J Birjand Univ Med Sci. 2013;19(6):26-32. Persian

19. Kalantari F, Hovsepian S, Haghighi S, Amini M. The prevalence of cardiovascular risk factors in patients with type 1 diabetes in Isfahan, Iran. Iran J Diabetes Lipid Disord. 2007;6(3):255-62. Persian

20. Sadeghi M, Roohafza H, Aghdak P, Kelishadi R, Shirani S. The prevalence of cardiovascular risk factors among women of central parts of Iran: Isfahan Healthy Heart Program. J Qazvin Univ Med Scie. 2005;9(2):76-83. Persian

21. Hosseini S, Zabihi A, Bijani A. Prevalence of cardiovascular risk factors in elderly population in Amirshahr (2007). Iran J Ageing. 2009;4(11):46-52. Persian

22. Esteghamati A, Meysamie A, Khalilzadeh O, Rashidi A, Haghazali $\mathrm{M}$, Asgari F, et al. Third national surveillance of risk factors of noncommunicable diseases (SuRFNCD-2007) in Iran: methods and results on prevalence of diabetes, hypertension, obesity, central obesity, and dyslipidemia. BMC Public Health. 2009;9(1):167.

23. Ayatollahi S, Ghoreshizadeh Z .Prevalence of obesity and overweight among adults in Iran. Obe Rev. 2010;11(5):335-7.

24. Ramachandran A, Wan Ma RC, Snehalatha C. Diabetes in Asia. Lancet. 2010;375(9712):408-18.

25. Sluijs I, Beulens JW, Spijkerman AM, Grobbee DE, Van der Schouw YT. Dietary intake of total, animal, and vegetable protein and risk of type 2 diabetes in the European Prospective Investigation into Cancer and Nutrition (EPIC)-NL study. Diabetes Care. 2010;33(1):43-8.

26. Ayatollahi SMT, Ghoreshizadeh Z. Prevalence of obesity and overweight among adults in Iran. Obes Rev. 2010;11(5):335-7.

27. Guh DP, Zhang W, Bansback N, Amarsi Z, Birmingham CL, Anis $\mathrm{AH}$. The incidence of co-morbidities related to obesity and overweight: a systematic review and meta-analysis. BMC Public Health. 2009;9(1):88.

28. Kaur G, Singh SP, Singh AP. Prevalence of overweight and obesity in urban and rural women of Punjab. Hum Bio Rev. 2013;2(4):30613

29. Basagoudar S, Chandrashekhar R. study of obesity and its risk factors among women of reproductive age group. Int J Cur Res Rev. 2013;5(3):23-8.

30. Mokdad AH, Ford ES, Bowman BA, Dietz WH, Vinicor F, Bales VS, et al. Prevalence of obesity, diabetes, and obesity-related health risk factors, 2001. JAMA. 2003;289(1):76-9.

31. Agheli N, Assefzadeh S, Rajabi M. The prevalence of cardiovascular risk factors among population aged over 30 years in Rasht and Qazvin. J Qazvin Univ Med Scie. 2005;9(2):59-65. Persian

32. Jardim TV, Sousa AL, Povoa TR, Barroso WS, Chinem B, Jardim $\mathrm{PC}$. Comparison of cardiovascular risk factors in different areas of health care over a 20-year period. Arq Bras Cardiol. 2014;103(6):493-501. 